\title{
Imperativo categórico e egoísmo: observações sobre a crítica de Schopenhauer a Kant
}

\author{
Categorical imperative and selfishness: comments on \\ Schopenhauer's criticism to Kant
}

\section{Aguinaldo Pavão}

Doutor em Filosofia pela Universidade Estadual de Campinas (Unicamp), professor do Departamento de Filosofia da Universidade Estadual de Londrina (UEL), Londrina, PR - Brasil, e-mail: aguinaldo.pavao@uol.com.br

\section{Resumo}

O artigo consiste num exame da alegação de Schopenhauer segundo a qual o imperativo categórico se apoia no egoísmo. Para o autor de Sobre o Fundamento da Moral, o imperativo categórico é apenas uma perífrase, um ornamento, uma expressão floreada da regra "não faças ao outro o que não queres que o outro te faça", a conhecida regra de ouro. Tento mostrar que as observações de Kant quanto à aplicação do imperativo categórico aos exemplos da falsa promessa e da indiferença com o sofrimento alheio são questionáveis. O modo como Kant apresenta tais exemplos dá ensejo a críticas razoáveis sobre o egoísmo ser a base do imperativo categórico. Apesar disso, argumento que é possível defender a tese de que o imperativo categórico, ao contrário do que pensa Schopenhauer, não se apoia em nenhuma forma de egoísmo. Quando Schopenhauer entende o imperativo categórico como princípio do egoísmo, ele pensa que os exemplos de aplicação do imperativo categórico contêm elucidações da motivação moral, o que não é o caso. 
Palavras-chave: Imperativo categórico. Egoísmo. Motivação moral. Agir racional.

\section{Abstract}

This article is an examination of Schopenhauer's claim that the categorical imperative is based on selfishness. According to author of On the Basis of Morality, the categorical imperative is merely a periphraris, a rhetorical expression of the rule 'do not do to others what you would not wish to be done to you,' the well-known golden rule. I attempt to show that Kant's remarks on applying the categorical imperative to the examples of false promise and of indifference to the suffering of others are questionable. The way Kant presents such examples gives rise to reasonable criticism on selfishness being the basis of the categorical imperative. Nevertheless, I argue that it is possible to defend the thesis that the categorical imperative, unlike Schopenhauer's thought, is not based in any form of selfishness. When Schopenhaver considers on the categorical imperative as the principle of selfishness, he thinks the examples of application of the categorical imperative include some elucidation of moral motivation, which is not the case.

Keywords: Categorical imperative. Selfishness. Moral motivation. Rational action.

\section{Introdução}

Neste artigo, pretendo examinar a alegação de Schopenhauer segundo a qual o imperativo categórico se apoia no egoísmo. Tento mostrar que as observações de Kant quanto à aplicação do imperativo categórico aos exemplos da falsa promessa e da indiferença para com o sofrimento alheio são questionáveis. Kant parece introduzir inadvertidamente ponderações prudenciais a fim de justificar a tese de que a não universabilidade de uma máxima tem de redundar na sua não aprovação moral. Daí ser compreensível que o modo como Kant apresente tais exemplos dê ensejo a críticas razoáveis sobre o egoísmo ser a base do imperativo categórico. Reconheço, pois, a pertinência da dificuldade apontada por Schopenhauer. Todavia, acredito que é possível defender a tese de que o imperativo categórico, ao contrário do que pensa Schopenhauer, não se apoia em nenhuma forma de egoísmo.

Embora Schopenhauer (1995, p. 114) frequentemente tente despachar sumariamente as teses das quais discorda com etiquetas nada 
favoráveis, chamando-as, por exemplo, de "palavrório oco", "quimeras" e "bolhas de sabão", não devemos nos deixar impressionar. A linguagem contundente e o estilo por vezes aguerrido precisam ser abstraídos. O que importa é perguntarmos se, por trás dessa forma veemente de tratar seus opositores, em especial a filosofia moral de Kant, há argumentos dignos de atenção que trazem à tona verdadeiras dificuldades. A meu ver, a resposta a essa pergunta é afirmativa. Schopenhauer realmente desenvolve uma leitura que faz emergir autênticas dificuldades que se fazem presentes na Fundamentação da Metafísica dos Costumes. Em Sobre o Fundamento da Moral encontramos muitas críticas à filosofia moral de Kant. Dentre essas críticas, Schopenhauer ataca o imperativo categórico kantiano haja vista este ter como base, segundo sua leitura, o egoísmo. De acordo com Schopenhauer, unicamente a compaixão pode ser considerada a motivação legítima das ações morais. Minha intenção aqui é bem restrita. Pretendo apenas examinar, com base em Sobre o Fundamento da Moral, a acusação de Schopenhauer (1995, p. 64) de que o imperativo categórico tem como base o egoísmo. Acredito que essa crítica captura um momento embaraçoso dos esclarecimentos dados por Kant ao sentido do imperativo categórico.

\section{0 argumento de Schopenhauer}

Antes de entrarmos na discussão da tese de que a base do imperativo categórico é o egoísmo, talvez seja oportuno distinguirmos, conforme adverte Schopenhauer (1995, p. 40), princípio de fundamento. Por "princípio" (Prinzip), deve-se entender a "proposição fundamental (oberste Grundsatz) mais elevada" da ética, que exprime concisamente uma prescrição para a ação, ou, numa ética não prescritiva, o modo de agir que tem valor moral. Enquanto o princípio expressa o hó ti, o que da virtude, o fundamento (Fundament), por sua vez, responde pelo dióti, o porquê, a razão (Weshalb) da virtude. O fundamento, pois, busca a razão pela qual uma ação é merecedora de louvor ou censura, podendo ser encontrado "na natureza humana" ou "nas relações do mundo exterior ou ainda em qualquer outro lugar". 
Postas assim as coisas, cabe perguntar: qual é, para Schopenhauer, o fundamento da moral em Kant? Parece ser, a se considerar o parágrafo seis de Sobre o Fundamento da Moral ("Sobre o fundamento da ética kantiana"), a razão pura prática, ou o fato da razão. E qual seria o seu princípio? O imperativo categórico. Porém Schopenhauer argumenta, no parágrafo sete, que o seu princípio é o egoísmo. Como pode o egoísmo ser o princípio de um fundamento como a razão pura prática? Se o fundamento é débil, também terá de ser débil o seu princípio. O egoísmo não teria de ser o fundamento do imperativo categórico? Ao que parece, considerando o que vem a seguir, Schopenhauer entende que o egoísmo é o princípio oculto da moral kantiana. É bom fixarmos isso, porque poderíamos pensar simplesmente que Schopenhauer estaria afirmando que o egoísmo é o que se encontra na Fundamentação da Metafísica dos Costumes, e que, embora não nomeado, tampouco seria intencionalmente ocultado a fim de não revelar inconsistências. Acontece que Schopenhauer (1995, p. 65) vai defender que Kant teria sido ardiloso no ocultamento do egoísmo como princípio da moral. Ora, esse é um tipo de acusação de outra ordem. Já não se trata tão-somente de mostrar inconsistências em Kant, mas de sondar suas intenções, sua subjetividade ao escrever o texto. Creio que o melhor que temos a fazer com essa perspectiva de leitura consiste simplesmente em desprezá-la. Explico-me: nada ganharíamos tentando acompanhar Schopenhauer em sua crítica aos supostos ardis de Kant ${ }^{1}$. O que merece atenção é o argumento de Kant, ou seja, o que cabe ponderar é se, uma vez sendo necessário reconhecer o egoísmo por trás do imperativo categórico, devemos reconhecer uma faceta nova, ou oposta às palavras de Kant, bem como assinalar a sua inconsistência com o fundamento sobre o qual ele acredita repousar a sua filosofia moral.

\footnotetext{
1 Tentarei seguir aqui a regra, assumida por Schopenhauer, segundo a qual "é justo interpretar um autor sempre pelo mais favorável” (SFM § 6: 39), isto é, procurando compreender 0 que 0 autor quis dizer. Tanto Kant como Schopenhauer serão lidos, analisados e confrontados levando-se em conta suas intenções. É evidente que estou me referindo aqui às intenções sondáveis a partir dos textos. Não se trata de forma alguma de procurar razões psicológicas que porventura teriam determinado a defesa de um ponto. Na verdade, é inofensiva a ideia de que um autor nem sempre se exprime de forma clara e de que o leitor possa, e mesmo deva, buscar nas entrelinhas a clareza possível das teses formuladas.
} 
Cabe, de imediato, perguntar: o que Schopenhauer entende por egoísmo? Egoísmo [Egoismus] para Schopenhauer (1995, p. 114) significa "o ímpeto para a existência e o bem-estar" [der Drang zum Dasein und Wohlsein], sendo "a motivação principal e fundamental, tanto no homem como no animal”2. E por que ele julga que o egoísmo estaria sustentando o imperativo categórico? A resposta de Schopenhauer (1980, p. 130) é dada numa instigante análise do modo como Kant aplica o imperativo categórico a certas máximas que resultariam moralmente reprovadas pelo teste que o seu princípio impõe, a saber, o princípio que reza: "age como se a máxima de tua ação se devesse tornar, pela tua vontade, em lei universal da natureza". Dois dos quatro exemplos ${ }^{3}$ são atacados, justamente os exemplos que se referem aos deveres para com os outros, porquanto o autor de Sobre o Fundamento da Moral não confere cidadania numa reflexão moral aos chamados deveres para com nós mesmos (SCHOPENHAUER, 1995, p. 28-29; 1995, p. 1264).

\section{A máxima da falsa promessa}

No exemplo da falsa promessa (cf. KANT, 1980, p. 130), temos de ponderar se uma máxima que determina uma promessa mentirosa, se universalizada, conseguiria ainda produzir os efeitos desejados. Ora,

\footnotetext{
2 Adoto, aqui, uma compreensão lata da noção de egoísmo em Schopenhauer. Faço isso justamente a fim de não prejudicar a comparação que pretendo fazer entre a sua filosofia moral e a de Kant. Com efeito, se entendermos que a diferença entre eu e não eu é uma nota característica do conceito de egoísmo, então certamente tudo que não envolvesse a indiferenciação metafísica que a filosofia de Schopenhauer defende como correspondente ao mundo como coisa-em-si, teria de ser relegado ao egoísmo. Penso que a crítica de Schopenhauer a Kant precisa ser avaliada mediante 0 emprego de uma noção que seja filosoficamente menos parcial de egoísmo, quer dizer, de um conceito neutro de egoísmo. Acredito que isso é possível. Em que pese Schopenhauer entender que a diferenciação entre eu e não eu é crucial no conceito de egoísmo, ele também entende, por vezes, 0 egoísmo num sentido mais lato como uma motivação cujo fim é o próprio bem do indivíduo (SCHOPENHAUER, A. Sobre o fundamento da moral. Tradução de Maria Lúcia Cacciola. São Paulo: M. Fontes, 1995. p. 131). Tomando nesse sentido geral, e sem assumir as premissas da metafísica schopenhaueriana, pode-se dizer que tal concepção não diverge da compreensão de Kant sobre o princípio do amor de si mesmo (KANT, 2002, p. 38).

3 Os exemplos oferecidos por Kant são: (i) suicídio, (ii) falsa promessa, (iii) desleixo dos dons naturais e (iv) indiferença com a desgraça e a miséria alheia, correspondem respectivamente aos deveres: (i) conservar a vida, (ii) prometer verazmente, (iii) desenvolver os talentos e (iv) ser benevolente. Os deveres (i) e (ii) seriam deveres perfeitos; (iii) e (iv) deveres imperfeitos. Os deveres (i) e (iii) são deveres para conosco mesmos; (ii) e (iv) deveres para com os outros.

4 Essa posição de Schopenhauer mereceria um tratamento específico, mas aqui será apenas mencionada.
} 
se tenho como lei universal da natureza que todos podem prometer falsamente quando se encontram em dificuldade, neste caso, quando qualquer promessa for feita, podemos considerá-la falsa. Logo, não será digna de crédito. Uma vez destruída a confiança recíproca entre as pessoas, eu não poderei mais prometer qualquer coisa, pois as promessas ficariam carentes de significado em tal ordem natural. E isso graças a simples razão de não ter sentido prometer o que não cumprirei a quem também sabe que não cumprirei. Neste exemplo, portanto, Kant quer mostrar a impossibilidade de uma lei universal da natureza da falsa promessa. Assim sendo, o ponto está na contradição intrínseca da máxima; e justamente por esta razão, deve ser reprovada moralmente.

Agora, quando Kant, no fim deste exemplo, afirma que, se a máxima da falsa promessa fosse universalizada, "ninguém acreditaria em qualquer coisa que lhe prometessem e rir-se-ia apenas de tais declarações como de vãos enganos" (KANT, 1980, p. 131), ele desloca a argumentação de reprovação moral da máxima da contradição interna para a contradição que poderíamos chamar extrínseca. Ou seja, não se trata mais, a rigor, de um argumento moral (no sentido kantiano), mas prudencial. Se tomássemos esta afirmação de Kant como base para censurarmos moralmente a máxima em questão, nós teríamos uma justificação que corresponderia aos interesses particulares da pessoa com intenção de fazer uma falsa promessa. Essa pessoa renunciaria ao ato não em virtude da contradição interna de sua máxima (só neste caso a renúncia teria valor moral), mas sim em função das consequências nocivas que recairiam sobre si se a máxima fosse universalizada. Trata-se, em suma, do deslocamento dos móbiles, princípios subjetivos do desejar (cf. KANT, 1980, p. 134). No primeiro argumento o móbil é moral; no segundo não, pois aí eu agiria conforme ao dever por intenção egoísta, mas não conforme ao dever por dever (aus Pflicht). Parece, portanto, que Kant se engana na última frase do exemplo da falsa promessa (sobre esse ponto voltarei quando tratar do quarto exemplo).

Ora, é essa justamente a percepção de Schopenhauer. Ele aponta, pois, a suposta base egoísta do imperativo categórico já no exemplo da falsa promessa, ao passo que geralmente esse problema parece surgir apenas com o quarto exemplo, o da filantropia. De acordo com 
Schopenhauer, o exemplo da falsa promessa já revela que o imperativo categórico, ao exigir a universalidade da máxima, tem em vista os reclames do egoísmo que pensa nas consequências dessa universalização considerando o eu não apenas como a parte ativa, mas também, e principalmente, como a parte passiva. Assim, a adoção de uma máxima de promessas verazes, ou, em geral, a decisão pela justiça, não ocorre em vista do prazer que se tem em ser justo, mas pelo prazer que se tem em ser tratado de modo justo (cf. SCHOPENHAUER, 1995, p. 65).

\section{A máxima da ausência de caridade}

Passemos agora ao quarto exemplo. Nele, em que se apresenta, nas palavras de Schopenhauer, a "máxima da ausência de caridade" (SCHOPENHAUER, 1995, p. 66), Kant parece incorrer na mesma dificuldade que se encontra no fim do segundo exemplo, qual seja, a dificuldade sobre o móbil da ação. Kant argumenta que se poderia descobrir muitos casos em que a pessoa que deseja a universalização da máxima da indiferença "precise do amor e da compaixão dos outros e em que ela graças a tal lei natural nascida da sua própria vontade, roubaria a si mesma toda a esperança de auxílio que para si deseja" (KANT, 1980, p. 131). Ora, uma ação cujo móbil seja o medo das consequências não pode ser moralmente aprovada. De fato, isto não estaria de acordo com a ideia de uma vontade racional como Kant propõe, uma vez que esta vontade deve agir por respeito à lei e não por causa de um interesse particular (patológico).

A partir das considerações finais de Kant, no segundo e quarto exemplo, pode-se afirmar a pertinência da crítica de Schopenhauer. Mesmo que se alcancem conclusões menos desfavoráveis a Kant, é preciso reconhecer que Schopenhauer apontou para uma autêntica dificuldade na argumentação kantiana. Cabe, pois, examinar se a leitura de que o imperativo categórico seria "apenas uma perífrase, um ornamento, uma expressão floreada da regra por todo conhecida: quod tibe fieri non vis, alteri ne feceris" (SCHOPENHAUER, 1995, p. 68) é procedente. 


\section{A suposta base egoísta do imperativo categórico}

Ora, com relação à interpretação de que o imperativo categórico poderia ser reduzido à regra de ouro, é preciso destacar o que Kant na "Fundamentação" diz sobre o princípio não fazer ao outro o que não quero que o outro me faça. Kant claramente rejeita esse princípio. A oposição ao princípio Quod tibi fieri non vis, alteri ne feceris se dá num contexto em que Kant está a explicar a aplicação da segunda formulação do imperativo categórico com referência ao exemplo de "não mentir". Como se sabe, a segunda fórmula do imperativo categórico reza: "Age de tal maneira que uses a humanidade, tanto na tua pessoa como na pessoa de qualquer outro, sempre e simultaneamente como fim, e nunca simplesmente como meio" (1980, p. 135). Nesse sentido, Kant elucida que um indivíduo que intenciona fazer uma promessa mentirosa facilmente reconhece servir-se de outro homem simplesmente como meio. Assim, ele pode perceber a imoralidade de sua máxima, pois ele deixa de tratar os seres racionais como fins em si (KANT, 1980, p. 136-137). Pois bem, o que mais interessa aqui é a nota a essa explicação. Nessa nota lemos:

Não vá pensar-se que aqui o trivial: quod tibi non vis fieri, etc., possa servir de diretriz ou princípio. Pois este preceito, posto que com várias restrições, só pode derivar daquele; não pode ser uma lei universal, visto não conter o princípio dos deveres para consigo mesmo, nem os dos deveres de caridade para com os outros (porque muitos renunciariam de bom grado a que os outros lhe fizessem bem se isso os dispensasse de eles fazerem bem aos outros), nem mesmo finalmente o princípio dos deveres mútuos, porque o criminoso poderia por esta razão argumentar contra os juízes que o punem, etc (KANT, 1980, p. 136).

Realmente, o não fazer ao outro o que não quero que o outro me faça somente seria aplicado em relação aos outros e, portanto, não permitiria pensar num princípio moral que se referiria também aos deveres que tenho com relação a mim mesmo (por exemplo, para Kant, o dever de conservar a vida e cultivar os talentos). Tampouco autorizaria pensar a exigência moral da caridade, pois a caridade é um "fazer ao outro", isto é, envolve positividade da relação que tenho com o outro, ao 
passo que, se me oriento apenas pelo princípio de não fazer ao outro o que não quero que o outro me faça, ajo apenas de modo a evitar causar danos ao outro, mas não a promover o seu bem. Mesmo que se pensasse o princípio em termos positivos ${ }^{5}$, pode-se dar o caso, como diz Kant, que eu dispense a ajuda dos outros e, assim, não esperando que os outros me ajudem, não reconheça o dever de ajudá-los. E para consumar a incongruência do imperativo da moralidade com a regra de ouro, Kant fala da escusa do criminoso. Essa escusa possivelmente consistiria na alegação de que fico isento do cumprimento do meu dever se isento também o outro do cumprimento do seu dever. Como se vê, Kant está atento à possibilidade de compreensão do imperativo categórico como um princípio apoiado na ideia de reciprocidade moral entre os agentes. É preciso admitir, porém, que o fato de Kant estar atento a esse ponto não é suficiente como resposta à crítica de Schopenhauer. Com efeito, Schopenhauer corretamente dirige seu olhar crítico à noção de poder querer (wollen können) empregada por Kant e que tem papel central na compreensão do imperativo categórico.

A meu ver, temos de conceder a Schopenhauer a falta de clareza de Kant com respeito ao sentido do poder querer (wollen können). De fato, Kant não deixa suficientemente claro "o que posso e o que não posso propriamente querer" (SCHOPENHAUER, 1995, p. 64). Todavia, como já observado, é recomendação do próprio Schopenhauer "interpretar um autor sempre pelo mais favorável” (SCHOPENHAUER, 1995, p. 39). Ora, acolhendo essa recomendação, é necessário conter o açodamento na conclusão sobre se a ética de Kant é, no fundo, egoísta ou não.

Sob essa perspectiva, parece-me oportuna uma observação sobre o sentido de uma ação racional em Kant. O sentido mais básico de uma ação racional equivale a agir com base em razões. Porém, pode-se alegar que agir com base em razões é apenas o significado mais imediato de uma ação racional. Podemos pensar num sentido mais forte para a ideia de um indivíduo que age racionalmente. Podemos pensar que

5 Justamente o ponto de Schopenhauer. Ele afirma que o imperativo categórico seria "apenas uma perífrase, um ornamento, uma expressão floreada da regra por todos conhecida: quod tibe fieri non vis, alteri ne feceris, a saber, quando a repetimos sem o non e o ne, para que esta livre-se da mácula de conter só os deveres de direito e não os de caridade" (SCHOPENHAUER, 1995, p. 68). 
esse indivíduo age com base na razão moral e que aquilo que ele pode querer nesse sentido também tem de poder ser querido por qualquer ser racional. Quando Kant afirma "temos que poder querer que uma máxima da nossa ação se transforme em lei universal: é este o cânone pelo qual julgamos moralmente em geral" (KANT, 1980, p. 131), acredito ser possível defender que o poder querer tem sentido contrário às inclinações e interesses fundados em nossa natureza sensível desejante, na qual se funda o princípio do bem-estar e do amor de si mesmo.

Por certo, a alegação anterior não é a única e provavelmente não seja a melhor, haja vista requerer a discussão adicional - que não é o objetivo deste artigo - sobre se a ética kantiana explica melhor que a de Schopenhauer nossos conceitos morais básicos. Acredito que a melhor resposta que se pode oferecer contra a crítica de Schopenhauer já se encontra em Kant. Ela consiste basicamente na alegação de que a universabilidade de uma máxima não é uma condição suficiente para a qualificação moral das ações. A aprovação da máxima no teste da universalização, seja mediante "poder pensar" seja mediante o "poder querer", satisfaz apenas uma condição necessária. Precisamos pensar na motivação moral e, nesse caso, é insuficiente o teste da universabilidade da máxima ${ }^{6}$.

Voltemos ao Sobre o Fundamento da Moral (SCHOPENHAUER, 1995, p. 123). Aí Schopenhauer procura reforçar sua crítica citando uma passagem da Crítica da Razão Prática (KANT, 2002, p. 111). Eis a passagem: "se [cada um] olhasse com inteira indiferença para a necessidade

\footnotetext{
6 Assim, pode-se dizer que Schopenhauer deu atenção excessiva aos exemplos da Fundamentação, não levando em conta a própria advertência de Kant nessa obra. "É preciso não perder de vista que não se pode demonstrar por nenhum exemplo [durch kein Beispiel], isto é, empiricamente, se há por toda a parte um tal imperativo [categórico]; mas há a recear que todos os que parecem categóricos possam, afinal, ser disfarçadamente hipotéticos. Quando, por exemplo, dizemos: 'não deves fazer promessas enganadoras', admitimos que a necessidade desta abstenção não é somente um conselho para evitar qualquer outro mal, como se disséssemos:'não deves fazer promessas mentirosas para não perderes 0 crédito quando se descobrir o teu procedimento'; admitimos, pelo contrário, que uma ação desse gênero tem de ser considerada como má por si mesma, que o imperativo da proibição é, portanto, categórico; mas não podemos encontrar nenhum exemplo seguro em que a vontade seja determinada somente pela lei, sem qualquer outro móbil, embora assim pareça; pois é sempre possível que o receio da vergonha, talvez também a surda apreensão de outros perigos, tenham influído secretamente sobre a vontade" (KANT, I. Fundamentação da metafísica dos costumes. Tradução de Paulo Quintela. São Paulo: Abril Cultural, 1980. p. 128).
}

Rev. Filos., Aurora, Curitiba, v. 24, n. 34, p. 81-94, jan./jun. 2012 
de outros, e, se tu também pertencesses a uma tal ordem de coisas, como irias estar de bom grado nela com o assentimento de tua vontade?" (KANT 2002, p. 111). Antes de oferecer uma explicação a essa passagem que mostre que ela não serve de abono à interpretação de que o imperativo categórico teria como base o egoísmo, é importante considerar o que Kant tem em mira no contexto do trecho citado. A passagem é extraída da seção intitulada "Típica da faculdade de julgar prática pura" . Kant procura, nessa parte da Crítica da Razão Prática pensar na ideia de uma ordem natural que sirva como um modelo a fim de que leis práticas possam ser pensadas in concreto (cf. BECK, 1966, p. 158). Se a máxima que pretendo assumir como guia de minha ação não puder compor tal ordem natural legal, ela tem de ser rejeitada. Por que ela tem de ser rejeitada? Podemos oferecer a seguinte resposta: i) ela colidiria com minha própria vontade e (ii) ela não poderia ser consistentemente querida por seres racionais autolegisladores de uma ordem moral (que, como tal, assumem a posição de legislarem para todos os seres racionais). A segunda resposta precisa ser compreendida a partir da ideia de que o ser racional se serve do modelo da legalidade natural apenas porque isso serve como termo intermediário no seu ajuizamento prático. O ponto de Kant é, pois, relativamente simples. Se minhas máximas são inaptas a comporem uma ordem legal, vale dizer - embora redundante -, universal, elas revelam-se imorais porque não poderão assentar-se em outra base que não o particularismo desejante do sujeito, isto é, justamente no seu egoísmo (sempre empírico). Pode-se dizer que a reprovação moral da máxima no teste da universalização implica necessariamente a natureza egoísta dela (da máxima). É verdade que disso, por si só, não se segue que, uma vez aprovada, a máxima não será egoísta. Apenas se alcança o resultado de que ela necessariamente seria egoísta se reprovada no teste. Uma vez aprovada no teste, é preciso que se assuma, adicionalmente, como fundamento determinante da vontade a própria lei moral, não a vantagem de participar de uma ordem legal em que tratamentos recíprocos estão

7 KANT, I. Crítica da razão prática. Tradução com introdução e notas de Valério Rohden. São Paulo: M. Fontes, 2002, livro primeiro, segundo capítulo, segunda seção. 
garantidos. Sobre isso, Kant é claro na seguinte declaração (não citada por Schopenhauer):

Ora, cada um sabe bem que, se ele [...] sem ser notado é desumano, nem por isso todos também o seriam imediatamente contra ele; por isso esta comparação da máxima de suas ações com uma lei natural universal não é tampouco o fundamento determinante de sua vontade. Mas esta lei é, contudo, um tipo do ajuizamento daquela máxima segundo princípios morais. Se a máxima da ação não é constituída de modo tal que resista à prova na forma de uma lei natural em geral, ela é moralmente impossível [sittlichunmöglich] (2002, p. 111).

Kant afirma, pois, expressamente que a aprovação da máxima pelo teste da universabilidade não pode (não deve) ser o "fundamento determinante" (Bestimmungsgrund) da vontade. O que se consegue com o teste é justamente a revelação de que a máxima é moralmente impossível, o que interpreto como sendo inconcebível em termos morais pensar a universabilidade ou querer a universabilidade de uma máxima que não pode compor uma ordem natural universal. Portanto, o que Kant diz na sequência da passagem citada em Sobre o Fundamento da Moral mostra que Kant estava atento à possibilidade de alguém pensar que o critério da universabilidade de uma máxima fosse já uma condição suficiente da sua moralidade ${ }^{8}$.

\section{Considerações finais}

Antes de concluir, gostaria de mencionar uma possível defesa de Schopenhauer. Cartwright (2005), em aparente defesa de Schopenhauer sobre a leitura do imperativo categórico como egoísmo, reconhece que alguém poderia criticar Schopenhauer afirmando que Kant não tinha o

8 Beck, em comentário à "Típica da faculdade de julgar prática pura" da Crítica da Razão Prática, corretamente diz: "A universabilidade de uma máxima é um teste negativo de sua validade como lei. Muitas máximas podem de fato ser universalizadas embora não tenham 0 status de lei. Desta forma 0 tipo da lei moral como uma lei natural uniforme e universal é apenas um critério negativo para 0 julgamento moral" (BECK, L. W. A commentary on Kant's critique of pratical reason. Chicago: The University of Chicago Press, 1966. p. 160). 
objetivo de fixar, com seus exemplos, a motivação para seguirmos a lei moral. Segundo o comentarista,

Schopenhauer é consciente da explicação de Kant sobre a motivação moral, mas acha que ela é insustentável por diversas razões. Ele ilustra alguns desses problemas que acompanham a ética não empírica de Kant, notando que o "próprio Kant confessa [...] que não temos nenhum exemplo absolutamente certo de uma disposição de agir por dever"(CARTWRIGHT, 2005, p. 259).

Ao que parece, Cartwright pensa, acompanhado de Schopenhauer, que somente uma perspectiva empírica para a ética poderia conferir significado aos nossos conceitos morais básicos. Ora, a colocação nesses termos da leitura de Schopenhauer do imperativo categórico é justamente a que evitei aqui. Ou seja, procurei desviar-me de uma discussão sobre qual teoria moral oferece maiores vantagens explicativas. Meu propósito foi tão somente verificar se a interpretação de Schopenhauer de que o imperativo categórico se apoia no egoísmo faz justiça ao que Kant diz sobre o assunto. Acredito que não faz. Em resposta a Cartwright, poderia dizer o seguinte. Em Kant há (e tentei mostrar que de fato há) uma distinção entre um critério para o ajuizamento de máximas que seriam ou não aptas para uma legislação moral e a motivação moral, isto é, princípio de determinação da vontade, o móbil que incorporamos em nossas máximas. Sendo assim, a alegação de Cartwright de que Schopenhauer estava ciente da explicação de Kant sobre a motivação moral e discordava dela não é boa. Com efeito, a leitura do imperativo categórico feita por Schopenhauer continuaria equivocada. Quando Schopenhauer entende o imperativo categórico como princípio do egoísmo, ele pensa que os exemplos de aplicação do imperativo categórico contêm elucidações da motivação moral, o que não é o caso.

\section{Referências}

BECK, L. W. A commentary on Kant's critique of pratical reason. Chicago: The University of Chicago Press, 1966. 
CARTWRIGHT, D. Schopenhauer's narrower sense of morality. In: JANAWAY, C. The Cambridge companion to Schopenhauer. New York: Cambridge Univesity Press, 2005, p. 252-292.

KANT, I. Fundamentação da metafísica dos costumes. Tradução de Paulo Quintela. São Paulo: Abril Cultural, 1980.

KANT, I. Werke in Zwölf Bande. Editado por W. Weischedel. Frankfurt: Surkamp, 1991.

KANT, I. Crítica da razão prática. Tradução com introdução e notas de Valério Rohden. São Paulo: M. Fontes, 2002.

SCHOPENHAUER, A. Über die Grundlage der Moral. In: SCHRIFTEN, K. Sämtliche Werke. Frankfurt am Main: Suhrkamp, 1998. v. 3, p. 629-815.

SCHOPENHAUER, A. Sobre o fundamento da moral. Tradução de Maria Lúcia Cacciola. São Paulo: M. Fontes, 1995.

Recebido: 28/08/2011

Received: 08/28/2011

Aprovado: 10/02/2012

Approved: 02/10/2012 